\title{
DE LA VIOLENCIA AL AMOR, LA DESMITIFICACIÓN ROMÁNTICA: UN ANÁLISIS CON PERSPECTIVA DE GÉNERO
}

FROM VIOLENCE TO LOVE, ROMANTIC DEMYSTIFICATION: A GENDERED ANALYSIS

Jorge García Villanueva, Claudia Ivonne Hernández Ramírez, Osiris Yomar Aparicio Hernández

Universidad Pedagógica Nacional, México

Correspondencia: jvillanueva@upn.mx

\section{RESUMEN}

La idea del amor romántico es un producto cultural que se ha construido desde la narrativa difundida en diversos textos literarios que se han encargado de mostrar enseñanzas que a través del tiempo han contribuido a identificar los comportamientos, las conductas, los sentimientos y las emociones como naturales y morales designadas diferencialmente para mujeres y hombres. Se cree que el amor es único, verdadero y complementario y a cada persona se le educa de una manera particular y diferente. El presente escrito tiene el propósito de reflexionar en torno a la construcción del amor romántico y desmitificar las ideas que se siguen perpetuando por medio de significados como los provenientes de los ámbitos familiar y religioso que perfilan la ilusión de la idealización sobre el amor, en específico, una relación únicamente entre hombre y mujer.

Palabras clave: amor romántico, violencia de género, heterosexismo, patriarcado, idealización romántica. 


\section{ABSTRACT}

The idea of romantic love is a cultural product that has been built from the narrative spread in various literary texts that have been responsible for showing teachings that over time have helped to identify the behaviors, behaviors, feelings and emotions as natural and moral designed differently for women and men. It is believed that love is unique, true and complementary and each person is educated in a particular and different way. The present writing has the purpose of reflecting on the construction of romantic love and demystifying the ideas that continue to be perpetuated through meanings such as those coming from the family and religious environments that outline the illusion of idealization about love, specifically, a relationship only between man and woman.

Key words: romantic love, gender violence, heterosexism, patriarchy, romantic idealization.

\section{INTRODUCCIÓN}

Desde el tiempo de Platón el amor era descrito como la belleza, la verdad y el bien, es decir, era como alcanzar la inmortalidad. En el año 380 a. C./2006, Platón diferenció entre tres formas de amor:

- Eros: pasión, sexo y erotismo

- Ágape: amor incondicional, profundo, reflexivo y altruista

- Philia: amor fraternal que incluye la amistad y el afecto sin excluir las relaciones sexuales

Al respecto, Fisher (1992) menciona que el amor se puede estudiar desde una perspectiva sociocultural y desde la biología para entender cómo funciona el cerebro en este proceso humano. Cada sociedad tiene una 
concepción sobre el amor y ésta varía dependiendo la cultura, creencias, normas sociales y estructuras mentales, elementos que permiten comprender la constitución del concepto, su evolución en el tiempo y el espacio (Gómez, 2011).

La idea del amor romántico es un producto cultural que se ha construido desde la narrativa mítica, las leyendas, los cuentos, las novelas, las películas y la música porque a través de las enseñanzas han mostrado lo que se considera "natural y normal", es decir, lo que significa ser mujeres y hombres; el amor romántico también ha sido un medio de control social en el que todo está determinado y es normativo (Fisher, 1992).

Otros supuestos sobre el amor plantean que las mujeres necesitan más amor que los hombres, se piensa que las mujeres usan el coqueteo como trampa mortal, que el amor es un mal necesario y que el fin no es el erotismo ni la pasión sino un enamoramiento que busca atrapar a un hombre. Además, el amor se caracteriza por un estado extraordinario que tiene fuerte implicación emocional con otra persona y puede llegar a desarraigar a la persona de su mundo, es considerado un fenómeno subversivo porque llega a alterar el orden social y la vida cotidiana, por lo tanto, se puede pensar que es peligroso (Gómez, 2011).

De acuerdo con Bard (2018) el amor se aprende desde los discursos sociales heteronormativos y de las relaciones familiares, donde tanto la exclusividad como la posesividad se corresponden, esto es, con la estructura y representación de la familia nuclear y heteronormativa de la sociedad. El amor aprendido en el modelo de familia heteropatriarcal, se expresa en síntomas como los celos, cuyas expresiones habituales son la posesividad, dependencia, ansiedad, agresividad, etcétera. 
El presente texto tiene el propósito de reflexionar en torno a la construcción del amor romántico y desmitificar las creencias e ideas que se siguen perpetuando a través de discursos como el familiar y religioso que se han encargado de perfilar la ilusión de la idealización sobre el amor, en específico, en una relación únicamente entre hombre y mujer.

\section{El género como elemento analítico}

Las sociedades clasifican qué es "lo propio" para las mujeres y los hombres, y desde esas ideas culturales se establecen las obligaciones sociales para cada sexo, con una serie de prohibiciones simbólicas. Al respecto, Lamas (2002) menciona que el género funciona como una especie de "filtro" cultural con el cual se interpreta al mundo, y también como una especie de armadura con la que se constriñen las decisiones y oportunidades de las personas dependiendo de si tienen cuerpo de mujer o de hombre. El género es un componente que está presente en la vida de las personas, determina y controla distintos aspectos sin que éste se vea como anómalo en el acontecer cotidiano (Serret y Méndez, 2011).

El término está en constante crecimiento y difusión mundial lo cual ha permitido la develación de estudios y análisis que cuestionan las premisas biologistas, esencialistas y universalistas con las que se han concebido las diferencias, así como la lógica binaria y jerárquica en las que se apoyan, de problematizar la exclusión, silenciamiento o tratamiento sesgado de la condición de las mujeres en los principales cuerpos de teoría (Bonder, 1998; Tarrés, 2012).

Las ideas y los significados que se le atribuyen a lo femenino y a lo masculino son construcciones culturales, están determinadas histórica y culturalmente (Secretaría de Educación Pública [SEP] y Programa 
Universitario de Estudios de Género [PUEG], 2010). De acuerdo con Gómez (2009) cuando se utiliza el género como una categoría permite comprender las relaciones de subordinación y dominación que existen entre mujeres y hombres, la desigualdad en la distribución de poder entre los sexos y cómo influyen en el desarrollo de las capacidades personales, profesionales y sociales.

"La cultura marca a los sexos con el género y el género marca la percepción de todo lo demás: lo social, lo político, lo religioso, lo cotidiano" (Lamas, 2000 , p. 4). Aunque las ideas sobre el género se modifican a lo largo del tiempo y del espacio, y las aportaciones al campo permiten develar que no sólo el término se relacione con las mujeres sino que refiera a los hombres que también se enfrentan a situaciones de desventaja y discriminación en la sociedad.

Hablar de género es situarse en una categoría histórica, política, cultural y analítica que recupera el pensamiento feminista el cual permite cuestionar el papel subordinado de las mujeres en todas las esferas de la vida social (Butler, 2006; Fonseca, 2008; Guerra, 2016; Matud, Rodríguez, Marrero y Carballeira, 2002; SEP y PUEG, 2010; Valenzuela, 2016). Además de discutir la raíz de la sujeción a un sesgo dominante de lo masculino. Es criticar el sistema universal de valores que ha mantenido la perpetuación opresora al posicionar a las mujeres a la obediencia hacia el mandato patriarcal que divide los espacios de lo público y lo privado y enfatiza tareas reproductivas y del hogar a un sector de la población: las mujeres (De Barbieri, 1992).

Serret y Méndez (2011) mencionan que "la cultura asigna identidades diferenciadas a sujetos a partir de una apreciación de su apariencia 
biológica, sexual, y al explicar por qué esas diferencias se interpretan como desigualdades, la teoría feminista se torna en una teoría del género" (p. 35), es decir, el concepto de género ha sido construido desde una inquietud política, y representa un instrumento de análisis para explicar y describir las relaciones de poder entre hombres y mujeres.

Según García y Hernández (2016) la sociedad es la encargada de fabricar las concepciones de cómo deben ser los varones y las mujeres porque es gracias a esa enseñanza diferenciada que ambos desarrollan capacidades y habilidades distintas, además de que depende también del momento histórico y sociocultural que acontezca. De lo que se trata es de comprender que el género (Ramos, 1997) es el resultado de un proceso de producción de normas culturales sobre el comportamiento de hombres y mujeres en interacción con las instituciones culturales, sociales, políticas y religiosas que permiten develar cuáles son las conductas que se consideran legítimamente masculinas y femeninas.

En este sentido, tanto a las mujeres como a los hombres se les ha atribuido características conductuales, por ejemplo; a ellas se les asignan atributos como ser tiernas, dulces, débiles, maternales, sentimentales y poco racionales. A los hombres se les adjudica el papel de proveedores, fuertes, poderosos, competitivos, capaces de enfrentar cualquier adversidad en el ámbito público (García y Hernández, 2016) lo que ha configurado y retratado una imagen rígida e inamovible para las personas.

\section{Prejuicios religiosos que fomentan la violencia en el amor romántico}

En México, la religión católica es la que más adeptos tiene $82.9 \%$, de acuerdo con el INEGI (2016), la influencia religiosa tiene un impacto entre la población y se ha encargado de mantener los mitos con los que se ha 
construido la concepción del amor romántico, las creencias han calificado de pecadoras, tentadoras, sumisas y sacrificadas a las mujeres desde el nacimiento. Siguiendo esta idea, Scott (1996) ejemplifica estas creencias de la siguiente forma:

La virgen de Guadalupe representa la obediencia y pureza (virginidad) el significado simbólico está en ser madre y ser sumisa. Adán y Eva, representan el ejemplo de pareja y se dice que Eva nació de la costilla de Adán lo que simbólicamente significa que es para estar en dominación, Eva no resulta ser la mujer ideal para Adán porque por su culpa los expulsan del paraíso (el Edén) por tentar a Adán y como consecuencia son castigados, pero Eva es la más afectada:

Y Dios dijo a la mujer: “¿Por qué lo has hecho?”, y contestó: "La serpiente me sedujo y comí." Dios dijo a la mujer: "Tantas haré tus fatigas cuantos sean tus embarazos: con dolor parirás los hijos, hacia tu marido irá tu apetencia, y él te dominará" (Génesis 3:16).

Este discurso es enseñado desde el catecismo, escuela católica o en una familia religiosa durante la infancia, se le inculca a niñas y niños una imagen de hombres y mujeres, pero se enfatiza que como castigo las mujeres tendrán partos dolorosos y dominación masculina siempre. Pero, ¿qué pasaría si anterior a Eva hubiese existido otra mujer hecha para Adán que no cumplió sus expectativas y por eso crearon a Eva?

“¿Has oído hablar de Lilith? Cuenta la leyenda que fue creada del mismo barro que Adán. Cuando ambos se miraron, se reconocieron y desearon estar juntos. Pero, Adán quiso imponer su poder viril a Lilith y someterla. 
Ella dijo: "Si somos iguales puesto que nacimos al mismo tiempo, ¿por qué he de estar yo abajo y tú encima?" Acto seguido, escapó corriendo. Adán quería alcanzarla, pero ella era muy ágil, así que él pidió ayuda al Creador: "Envía a tres ángeles para que le transmitan a Lilith que la mujer ha de obedecer al varón y someterse a él." Ella no estuvo de acuerdo con esta premisa, así que abandonó para siempre el paraíso y se refugió en el lado oscuro de la luna" (Orihuela, 2014).

El simbolismo de este discurso es vital para comprender la conformación del estereotipo de identidad femenina:

- Una mujer que cuestiona al hombre sobre por qué debe estar dominada si son seres iguales

- Una mujer es ágil

- No estar de acuerdo con la dominación y sometimiento masculino

- Abandonar al hombre

- Decir que se fue a vivir al lado obscuro

Parecieran cosas que cualquier mujer hace: ¿realmente son situaciones comunes o bien vistas socialmente? que una mujer cuestione a un hombre no es "correcto", pues las mujeres deben estar calladas y ser sumisas, el que sea una mujer ágil, que corre, que hace deportes "masculinos" según la sociedad tampoco es lo normal puesto que las mujeres son delicadas y femeninas, el abandono de un hombre tampoco, pues lo ideal es permanecer en la relación aunque exista violencia; lo ideal es que se quede con él a superar esos "obstáculos" porque las mujeres deben ser sufridas y luchar por salvar el amor, decir que se fue a vivir al lado obscuro, sería pensar que las mujeres son negativas, obscuras e impuras. 
Para la sociedad es mejor seguir creyendo en el mito de que Eva surgió de la costilla de Adán porque se acepta con mayor facilidad que las mujeres son obedientes, sumisas y calladas a nadie le gustaría ver a las mujeres libres, rebeldes y autónomas porque entonces rompen el ideal emblemático de obediencia, pureza y recato. Otro discurso relacionado con la ideología religiosa es aquel en el que se cree que el amor todo lo puede porque Dios es bueno y va a ayudar a las personas a salir de los problemas existentes con la pareja:

"El amor es paciente, es bondadoso. El amor no es envidioso ni jactancioso ni orgulloso. No se comporta con rudeza, no es egoísta, no se enoja fácilmente, no guarda rencor. El amor no se deleita en la maldad, sino que se regocija con la verdad. Todo lo disculpa, todo lo cree, todo lo espera, todo lo soporta" (Corintios 13:4-7).

Si se analiza la última frase de este párrafo: "todo lo disculpa, todo lo cree, todo lo espera, todo lo soporta", estas ideas suelen decirse a las niñas para que éstas aguarden pacientes para que encuentren al hombre ideal, también se les recomienda no ser egoístas, ni enojarse sino ser comprensivas, perdonar todo, creer y soportar todo lo que ellos les hagan y les digan. Esa sería una buena compañera, que quiere a su pareja, es fuerte, valiente que lucha por el amor, pero si hace lo contrario, será considerada una mala mujer.

De Beauvoir (1949) menciona que Eva no fue moldeada al mismo tiempo que el hombre si no fabricada con una sustancia diferente al barro de Adán ella fue extraída del flanco del primer varón, su nacimiento no fue autónomo; Dios no optó por crearla como un fin de sí misma, realmente fue para salvar a Adán de la soledad, ella tiene en su esposo su origen y fin. La carga 
simbólica religiosa ha hecho que mujeres, amigas, parejas, hijas y hermanas se vean afectadas moralmente y como género en particular, dependiendo las condiciones sociohistóricas y contextuales, es cómo se comprende el nivel de opresión que viven, es decir, las diferencias derivadas de una posición de clase, de acceso a medios de comunicación masiva e internet, la convivencia y relación con distintas formas de generación del conocimiento así como su modo de vida urbano, rural o vático son significativas para la construcción de grupos de mujeres, en resumen, la opresión se moldea de acuerdo con la clase, la etnia y el género (Lagarde, 2015).

La perpetuación del mito del amor romántico sigue contribuyendo a los lugares de opresión, del status quo patriarcal y capitalista, al seguir asociando a las mujeres a una feminidad única que las convierte en las proveedoras de afectos y cuidados, en la asignación de los roles de esposas y madres vinculadas con las instituciones sociales como el matrimonio, esto es, la vía legítima para combatir el pecado y la familia tradicional que tiene como fin la reproducción humana (Pascual, 2016), el concepto de ideal romántico ofrece un modelo de conducta amorosa que se encarga de estipular lo que significa enamorarse y las formas de sentir, comprender, expresar, definir y vivir, es decir, configuran los anhelos que construyen la subjetividad de las mujeres y los hombres (Flores, 2019).

Es importante resaltar que el concepto del amor romántico y sus mitos derivados están impulsados y sostenidos por la construcción social que se ha gestado y fraguado desde el sistema patriarcal que propicia las desigualdades de género, la discriminación hacia las mujeres, la sumisión, la abnegación, el sufrimiento, el ideal varonil y la heterosexualidad como la única expresión de la sexualidad (Alfaya, González y Olmedo, 2012; Ferrer y Bosch, 2013). 


\section{La construcción social del amor romántico}

Desde la sociedad se van conformando las normas, los mandatos de género y los castigos morales diferenciados para las mujeres y los hombres y es a través de las historias de amor, los mitos, las leyendas, las líricas, los poemas, los manuales instructivos asociados a pociones afrodisíacas y mágicas, los amuletos, las peleas entre enamorados, los lugares de encuentro amoroso, los secretos, las fugas y los suicidios son parte de la vida en las sociedades tradicionales en todo el mundo (Fisher, 1992). Culturalmente, se cree que solo existe un amor verdadero en la vida de las personas o que necesitan a su otra mitad o media naranja, a cada sexo se le educa de una manera particular y se legitiman actitudes y conductas diferenciadas entre hombres y mujeres. La familia representa la estructura ideológica que perpetua las diferencias y fomenta la construcción de esas diferencias a partir del género (Coronado, 2019).

Desde antes del nacimiento, comienza la atribución de características, dimensiones de vida, modos y concepciones del mundo, histórica y culturamente construidos entre los caracteres biológicos y sociales de la humanidad (Lagarde, 2015) que van construyendo y moldeando la feminidad y la masculinidad, la carga simbólica que asigna roles y estereotipos de género, hasta que la muerte los separe, es decir, una pedagogía perversa que coadyuva en la cosificación y apropiación de los mandatos hegemónicos de ser mujer y hombre.

Algunas características normalizadas constituyentes del ser mujeres se expresan de la siguiente manera (Bauman, 2015):

- Las niñas deben casarse y reproducirse

- A los niños les dicen que deben trabajar para mantener a su mujer e hijos/as 
- Las niñas son románticas y amorosas

- Los niños no demuestran sus emociones para no verse débiles

- Los hombres pueden tener más de una pareja pues demuestran su masculinidad

- Una mujer que tiene más de una pareja es una "puta"

- Las mujeres cuidan a los hijos/as y están a cargo de la limpieza del hogar

Las personalidades de hombres y mujeres se van conformando a lo largo de la historia según el tipo de educación que reciban, es lo que constituye los modelos de los ideales de cada ser de manera muy particular para cada sociedad (Mead, 1973). Las instituciones sociales son de suma importancia para el desarrollo social, como la familia, la escuela, las Iglesias, etcétera; la educación es un medio indispensable para los individuos porque dependiendo del tipo de formación es cómo se configura el comportamiento en la sociedad (Vygotsky, 1962).

La educación como otras instituciones socializadoras refuerza la concepción de feminidad y masculinidad, de acuerdo con los atributos asignados: a las mujeres, les corresponde el ser delicadas, tiernas, indecisas, dependientes, inseguras, dispuestas a servir a los demás, bellas y seductoras. A los hombres, les corresponde el ámbito del poder, lo racional y la toma de decisiones, por lo que han de ser inteligentes, independientes, agresivos, dominantes, controladores y combativos.

Esta clasificación sobre los atributos de las mujeres y de los hombres, lleva al sexismo y a la discriminación hacia las mujeres, en general, por considerar que lo biológico determina por naturaleza los roles estereotipados de lo femenino y lo masculino, sin considerar que son resultado también de factores socioculturales en los cuales la familia, la escuela y los medios de 
comunicación masiva e internet contribuyen de manera significativa en los procesos de socialización.

La escuela cuenta con varios mecanismos de reproducción de estereotipos que van desde el currículum oculto, la organización y tipo de gestión, la normatividad educativa, la interacción entre docente y estudiante (Díaz, 2003), es decir, los recintos escolares realizan una reproducción intergeneracional de las clases sociales y de género, de estructuras de la vida social mediante la especialización de las subjetividades del alumnado y establece prácticas sociales características de cada sociedad.

Los estudios de género en la educación han permitido observar que la escuela, desde el nivel preescolar hasta el universitario, constituye una de las instancias de socialización por medio de las cuales se transmiten y fomentan, de manera directa o indirecta, una serie de estereotipos, marcando de este modo el "deber ser" de mujeres y hombres. Así, la educación formal, al igual que otras instituciones socializantes, fomenta y refuerza la concepción de feminidad y masculinidad, sustentada a partir de ciertas características, cualidades, rasgos, atributos, normas y valores que constituyen parte de la construcción de las identidades de hombres y mujeres. Aunque la escuela es hoy un ámbito público abierto para hombres y mujeres, reproduce la división sexual del espacio, es decir, cuando espacios que pueden ser usados por todas las personas, en ocasiones, se excluyen otras por cuestión de género (Bourdieu, 2000).

El patriarcado no es una dominación exclusiva de hombres hacia mujeres, el patriarcado busca la forma de dominar y oprimir a todas las sociedades, es una lucha de poder constante, una opresión genérica. De acuerdo con Lagarde (2015) el patriarcado es uno de los espacios históricos del poder 
masculino que encuentra su asiento en las más diversas formaciones sociales. La concepción que se fue formando del amor desde épocas antiguas, viene de un romanticismo hecho por hombres y para beneficio de ellos mismos como lo plantea Engels (1884) al decir que el derrocamiento del derecho materno fue la gran derrota histórica del sexo femenino en todo el mundo. La mujer se vio degradada, convertida en la servidora, en la esclava de la lujuria del hombre, en un simple instrumento de reproducción.

El amor romántico tradicional está construido por un sistema patriarcal cultural que maneja el Estado y los medios de comunicación masiva; el propósito del amor que venden los medios es el de formar una familia pero no una familia cualquiera sino la "familia tradicional", esa donde el hombre es el patriarca del hogar, la mujer no labora pero toda su vida hace trabajo no remunerado, su trabajo no remunerado aumenta y sufre círculos de violencia que son aceptados socialmente porque están normalizados por una cultura de la personalidad, además se reproduce. Venden el mito de la monogamia, enseña a relacionarse, reprime la sexualidad de las mujeres y el enamoramiento hacia un solo ser; un amor heterosexual y monogámico entra en la naturalidad, si llega a ser diferente ya no es natural ni aceptado (Engels, 1884; Lagarde, 2015).

\section{Mitos del amor romántico}

La cultura en la que cada ser humano se ha desarrollado va enseñando una forma muy particular de lo qué es el amor y es así como se va a aprendiendo a amar, cómo, cuándo, con quién sí y con quién no. Este modelo del amor romántico se va aprendiendo y construyendo dependiendo de las estructuras sociales en las que las personas se van desenvolviendo y es así como se van normalizando y justificando los comportamientos que generan violencia. 
En cada sociedad se aprende que el amor ideal es el amor romántico o amor pasional, en él son socializadas las mujeres y los varones (Caro y Monreal, 2017). Este amor, lleva inscrito mitos y creencias como las que el enamorarse no depende de la voluntad de la persona; el amor lo puede todo; el amor lo justifica todo; el amor es suficiente; provoca una entrega total a la persona amada; las dos personas se complementan, están hechas la una para la otra; el 'verdadero amor' es incondicional; es exclusivo y excluyente, no se puede compartir; el 'verdadero amor' dura siempre, si se acaba, no era 'amor auténtico'; el estado general que crea es de felicidad total.

A continuación, se presentan cuatro grupos que albergan distintos mitos sobre el amor romántico (Moreno y Sastre, 2011 en Caro y Monreal, 2017; Cubells y Calsamiglia, 2015; Herrera, 2007; Lagarde, 2001; Pascual, 2016):

\section{El amor todo lo puede}

- Este mito conlleva varias situaciones, lleva a creer que existe una transformación por amor, que alguien que violenta va a cambiar por amor.

- Lleva a una normalización del conflicto porque como el mito dice "el amor todo lo puede" y va a superar todos los obstáculos, es decir, todo tipo de violencia.

- Creer que los polos opuestos se atraen y es necesario que para que la relación sea perfecta los dos seres deben ser personalmente distintos.

- Creencia de que el amor verdadero perdona y aguanta absolutamente todo. 
El amor verdadero predestinado

- La famosa frase y mito "mi media naranja" refiere a que los seres humanos están incompletos y que sólo pueden alcanzar la felicidad cuando tienen una pareja.

- La complementariedad es similar a la media naranja, los seres humanos necesitan tener a alguien para alcanzar la perfección de la mano de otra persona.

- Creencia de que sólo existe un amor verdadero en la vida y no pueden darse la oportunidad de conocer a alguien más porque la primera persona de la que se enamoran es con la que deben compartir toda la vida.

El amor es lo más importante y requiere entrega total

- Atribución de dar felicidad, se tiene una relación para poder hacer feliz a la pareja sin importar el bienestar personal.

- La entrega total, se habla de una entrega al $100 \%$ para que la pareja esté feliz, no importa dejar de lado la vida personal (familia, amistades, vida laboral, académica y/o profesional, actividades de ocio) no se vale realizar actividades por separado.

\section{El amor es posesión y exclusividad}

- Mito del matrimonio, se cree que solamente llegando al matrimonio ya es una relación completa y realizada y que los errores que se cometieron durante la etapa del noviazgo ya no sucederán; por ejemplo; si había una situación de violencia y de engaños con una tercera persona cuando se llega al matrimonio ya no sucederá porque ya ante la sociedad son "esposos". 
- Los celos son signo de amor y estos deben de ser indispensables en la relación para que se entienda que si hay amor verdadero.

- Fidelidad y exclusividad mito que se aplica más a las mujeres y como mujeres no pueden ser infieles y son propiedad exclusiva del hombre.

El amor romántico está impregnado en la estructura que dirige las emociones, el deseo, la satisfacción, la euforia y al igual que el resto de los impulsos, el amor romántico constituye una necesidad, produce ansias (Fisher 2004). El amor romántico inicia su construcción en las estructuras mentales porque se construye como una necesidad y esto ocasiona una ansiedad y desde la cultura se conforma una serie de significaciones que las personas construyen con base en su experiencia y la complejidad cultural (Lagarde, 2015).

En una investigación realizada con mujeres jóvenes que cursaban el nivel medio superior y que estaban en una relación de pareja se encontró que el anhelo más representativo con respecto a su ideal de pareja, se ubicaba en un modelo masculino que se enfocaba en el cuidado por el otro y la protección, deseaban a un hombre que acompañara a la pareja, que representara un papel activo en la relación, considerando que el desapego del hombre con respecto a la demostración de afecto y sentimientos es una constante en el sistema patriarcal. En el amor romántico se aspira a una pareja que demuestre sus sentimientos y que sea detallista en la relación, la forma en que un hombre toma posesión de dichas características es a través de un modelo masculino fuerte y protector (Flores, 2019).

En el caso de los hombres también tienen pensadas características deseables que esperan cubran las mujeres, como el ser atentas con la pareja, cariñosas, 
comprensivas, preocupadas por el otro y que procuren las demostraciones de amor en todo momento. De acuerdo con Lazarín (2003) se pueden afirmar dos cosas; la primera está orientada a comprender que los patrones deseables en las mujeres dentro del ideal romántico, es traducido a mujeres pasivas en la relación, reservadas para el terreno de lo privado y que deben tener presente que antes de ser para sí mismas, requieren ser para el otro.

La segunda se vincula con una profunda perpetuación del discurso proveniente de la familia patriarcal reforzado a través de los mitos románticos que han contribuido a fortalecer el ideal romántico, es decir, el deseo idealizado en una pareja está relacionado con el sistema patriarcal y la asignación de género, lo cual ha dado como resultado la generación de modelos de comportamiento que cambian dependiendo de si se es hombre o mujer en la relación (Caro y Monreal, 2017; Flores, 2019).

Otra investigación relacionada con las narrativas de mujeres sobre cómo conciben y viven el amor romántico, es que se identificaron dos momentos del amor romántico que se viven en las relaciones de pareja; en el primero, la violencia y el maltrato son manifestaciones de control que ejercen los hombres para permanecer en la relación y el segundo momento, es de sacrificio-fe que implica estar en la relación, se piensa que con paciencia, comprensión y tolerancia el hombre cambiará y será un buen padre y esposo. Al presentar actitudes de rol de género tradicionales se tiende a naturalizar la violencia contra las mujeres dentro de una relación de pareja y tienen más probabilidades de ser víctimas de violencia y de permitirla, por seguir sosteniendo la idea de que el amor todo lo puede (Coronado, 2019). 
Al respecto, Pascual (2016) menciona que el amor romántico es histórico y heredero del amor cortés, burgués y victoriano, se consolida en la dependencia entre hombres y mujeres, encuentra su justificación en una supuesta necesidad de complementación psicológica, de aceptación y asunción de concepción diferencial y complementaria en donde nacen los estereotipos, roles y mandatos de género que se encargan de reproducir esquemas desiguales entre las personas al pensar que la felicidad y el amor se puede encontrar al complementar su ser con otra persona.

\section{Reflexiones finales}

Es necesario desentrañar los discursos y las narrativas que han elaborado distintos agentes e instituciones sociales sobre la forma en cómo hombres y mujeres conciben el amor, para dejar de perpetuar la imagen de la espera, pasividad, cuidado, renuncia, entrega y sacrificio que está relacionada con el comportamiento de las mujeres y en el caso de los hombres alejarse del imaginario que posiciona a éstos en la imagen del héroe, conquistador, seductor, resistente, protector, salvador y dominador, es decir, se requiere desquebrajar la idealización de ofrecimiento y complementación entre las personas (Ferrer y Bosch, 2013), para dejar de pensar que esos estándares son las formas de expresar los sentimientos y emociones acordes a las normas sociales y culturales de las reglas que regulan las formas de conocer, acercarse e interactuar (Esteinou, 2017).

A través de la historia las mujeres han ocupado un lugar subordinado porque se piensa que sus características, capacidades y comportamientos son provenientes de la biología diferenciada, sin embargo, es preciso estudiar las circunstancias biológicas a la luz de una óptica ontológica, económica, social y psicológica (Martín, 2006; Hernández, 2014). De acuerdo con Cazés (2000) las mujeres y los hombres son construcciones 
sociales, culturales e históricas y por medio del proceso de inculcación y asimilación del género, la perpetuación de las relaciones de poder y los valores dominantes tanto en la familia como en la escuela que es como se va constituyendo una violencia simbólica insidiosa e invisible que se impregna en los cuerpos, en las emociones, los deseos y los comportamientos de las personas (Carbonell, 1996; Conway, Bourque y Scott, 1996; Gil y Lloret, 2007). Por ejemplo, el seguir pensando que expresar sufrimiento es el significado más grande que se le puede otorgar a la persona amada.

En el proceso de socialización romántica, a las mujeres se les enseña a que antepongan las necesidades de otros a las propias y la estereotipia de sumisión, pasividad, el deber de amar y falta de iniciativa se relacionan con las mujeres además de construir la subjetividad bajo la concepción de amor en la pareja a imagen y semejanza de amor maternal, altruista, incondicional y abnegado (Coronado, 2019). El amor romántico también se constituye en una trampa para los propios varones, quienes condenados a reproducir mandatos de género y búsquedas estereotipadas de lo que sería la mujer elegida, acaban presos de emociones patriarcales como los celos, la pulsión de control, la inseguridad permanente, así como la necesidad de demostrar heterosexualidad en cada práctica (Bard, 2018).

Es fundamental que el papel de la educación transversalice la noción del amor para reflexionar sobre su función en la vida de las personas y comprender que no es abstracto sino histórico que está circunscrito en un contexto social determinado y específico y genéricamente se enseña la acción de amar de forma distinta según el género de las personas. Aquí lo que subyace es dejar de creer y pensar que los seres humanos están incompletos, que los vínculos socioafectivos son perpetuos y el sufrimiento forma parte de las relaciones, la realidad es dejar de ver ideales de amor 


\section{en hombres y mujeres y comprender que el amor es un constructo social e histórico, que las personas sin distinción de género pueden reinventar diversas formas de expresar sus sentimientos y construir vínculos afectivos basados en el respeto, la empatía, la libertad, la reflexión, la solidaridad y la fraternidad (García, Hernández y Monter, 2019).}

\section{REFERENCIAS}

I Alfaya, G. M., González, J. E. y Olmedo, A. M. (2012). Maternidad, sociedad, cultura y religión: ¿conflicto de identidades? I Congreso Internacional de Comunicación y Género. Sevilla.

I Bard, W. G. (2018). Las violencias romantizadas: masculinidades hegemónicas en el capitalismo tardío y heteropatriarcal. Aposta. Revista de Ciencias Sociales, 77, 59-100.

I Bauman, Z. (2015). Amor líquido. México: Fondo de Cultura Económica.

I Bonder, G. (1998). Género y subjetividad: avatares de una relación no evidente. Programa Interdisciplinario de Estudios de Género (PIEG). Universidad de Chile: Chile.

I Butler, J. (2006). Regulaciones de género. Revista de Estudios de Género. La ventana, 23, 7-35.

I Carbonell, S. J. (1996). La escuela: entre la utopía y la realidad. España: Octaedro.

1 Caro, G. C. y Monreal, G. C. (2017). Creencias del amor romántico y violencia de género. International Journal of Developmental and Educational Psychology, 2(1), 47-56.

I Cazés, D. (2000). La perspectiva de género. Guia para diseñar, poner en marcha, dar seguimiento y evaluar proyectos de investigación y acciones públicas y civiles. México: Consejo Nacional de Población.

I Conway, J., Bourque, S. y Scott, J. (1996). El concepto de género. En M. Lamas. El género: La construcción cultural de la diferencia sexual. (pp. 21-33). México: UNAM/PUEG.

I Coronado, L. (2019). La violencia del amor romántico en la narrativa de dos mujeres mexicanas. Psicologia \& Sociedade, 31, 1-19.

I Cubells, J. y Calsamiglia, A. (2015). El repertorio del amor romántico y las condiciones de posibilidad para la violencia machista. Universitas Psychologica, 14(5), 1681-1694.

$\checkmark$ De Barbieri, T. (1992). Sobre la categoría de género. Una introducción teórica-metodológica. Revista Interamericana de Sociología, 2, 50-66.

I De Beauvoir, S. (1949). El segundo sexo. Paris, Francia: De Bolsillo.

I Díaz, R. A. (2003). Educación y género. México: Instituto de Investigaciones en Educación de la Universidad Veracruzana.

I Engels, F. (1884). El origen de la familia, la propiedad privada y el Estado. En https://www.marxists.org/ espanol/m-e/1880s/origen/el_origen_de_la_familia.pdf

I Esteinou, R. (2017). Intimidad y amor romántico entre 1900 y 1950 en México: discursos y normas. Cuicuilco. Revista de Ciencias Antropológicas, 24(68), 35-57. 
I Ferrer, P. V. y Bosch, F. E. (2013). Del amor romántico a la violencia de género. Para una coeducación emocional en la agenda educativa. Profesorado. Revista de currículum y formación del profesorado. 17(1), 105-122.

I Fisher, H. (1992). Anatomia del amor: historia natural de la monogamia, el adulterio y el divorcio. Barcelona: Anagrama.

I Fisher, H. (2004). Por qué amamos: naturaleza y quimica del amor romantico. Madrid: Taurus Ediciones.

I Flores, F. V. M. (2019). Mecanismos en la construcción del amor romántico. Revista de Estudios de Género. La ventana, 6(50), 282-305.

$\checkmark$ Fonseca, H. C. (2008). Aproximación teórica sobre la construcción cultural del género. En C. Fonseca H. y L. Quintero (coords.). Temas Emergentes en los Estudios de Género. (pp. 17-29). México: Porrúa.

$\checkmark$ García, V. J. y Hernández, R. C. I. (2016). ¿Realidad o fantasía? Roles y estereotipos sexistas expuestos a través de representaciones discursivas e iconográficas en cuentos infantiles. Revista Integra Educativa, 9(1), 1-20.

$\checkmark$ García, V. J., Hernández, R. C. I. y Monter, A. N. S. (2019). Amor romántico entre estudiantes universitarios (hombres y mujeres), una mirada desde la perspectiva de género. Revista de Estudios de Género. La ventana, 6(49), 218-247.

$\checkmark$ Gil, R. E. y Lloret A. I. (2007). La violencia de género. Barcelona: UOC.

I Gómez, H. (2011). La construccion sociocultural del amor romántico. Madrid: Fundamentos.

I Gómez, S. A. (2009). El sistema sexo/género y la etnicidad: sexualidades digitales y analógicas. Revista Mexicana de Sociología, 7(4), 675-713.

I Guerra, R. (2016). Persona, sexo y género. Los significados de la categoría género y el sistema sexo-género según Karol Wojtya. Open Insight, 7(12), 143-168.

I Hernández, R. C. I. (2014). Análisis de los elementos discursivos e iconográficos sexistas en dos cuentos infantiles de uso regular en escuelas de educación preescolar. (Tesis de Especialización). México: UPN.

I Herrera, C. (2007). Los Mitos del Amor Romántico en la Cultura Occidental. [Mensaje en un blog]. El Rincón de Haika, Recuperado de: http://w390w.gipuzkoa.net/WAS/CORP/DBKVisorBibliotecaWEB/ visor.do?ver\&amicus $=673603$

$\checkmark$ Lagarde, M. (2001). Claves feministas para la negociación del amor. Managua: Puntos de Encuentro.

I Lagarde, M. (2015). Los cautiverios de las mujeres: madresposas, monjas, putas, presas y locas. México: Siglo XXI.

1 Lamas, M. (2000). Diferencias de sexo, género y diferencia sexual. Cuicuilco, 7(18), 1-24.

$\checkmark$ Lamas, M. (2002). Cuerpo: Diferencia sexual y género. México: Taurus.

I Lazarín, M. F. (2003). Enseñanzas propias de su sexo. La educación técnica de la mujer 1871-1932. En: M. A. Arredondo (ed.). Obedecer, servir y resistir: la educación de las mujeres en la historia de México. México: Universidad Pedagógica Nacional, Miguel Ángel Porrúa.

I Martín, C. A. (2006). Antropología del género. Culturas, mitos y estereotipos sexuales. España: Cátedra/ Anaya.

$\checkmark$ Matud, A. P., Rodríguez, W. C., Marrero, Q. R. y Carballeira, A. M. (2002). Psicología del género: implicaciones en la vida cotidiana. España: Biblioteca Nueva. 
1 Mead, M. (1973). Sexo y temperamento en las sociedades primitivas. Barcelona: Laia.

I Orihuela, A. (2014). Hambre de hombre. México: Aguilar.

I Pascual, F. A. (2016). Sobre el mito del amor romántico. Amores cinematográficos y educación. Dedica. Revista de Educação e Humanidades, 10, 63-78.

I Platón (380 a. C./2006). El banquete. Madrid: Folio.

I Ramos, E. C. (1997). El concepto de género y su utilidad para el análisis histórico. La Aljaba, 2, 13-32.

I Scott, J. (1996). El género: una categoría útil para el análisis histórico. En M. Lamas. El género: La construcción cultural de la diferencia sexual. (pp. 265-302). México: UNAM/PUEG.

1 SEP y PUEG (2010). Equidad de género y prevención de la violencia en primaria. México: SEP/PUEG.

I Serret, E. y Méndez M. J. (2011). Sexo, género y feminismo. México: SCJN/ TEPJF/IEDF.

I Tarrés, L. (2012). A propósito de la categoría género: leer a Joan Scott. Soc. e Cult., Goiânia, 15(2), 379391.

1 Valenzuela, S. M. (2016). Las bases epistémicas de la concepción feminista de la ciudadanía. Revista Estudios Feministas, 24(1), 31-43.

I Vygotsky, L. (1995). Pensamiento y lenguaje. Trad. de María Margarita Rotger. Ediciones Fausto.

Envío a dictamen: 27 de noviembre de 2020

Reenvío: 13 de enero de 2021

Aprobación: 4 de febrero de 2021

Jorge García Villanueva. Doctor en Psicología por la Facultad de Psicología de la Universidad Nacional Autónoma de México (UNAM), profesor titular de la Universidad Pedagógica Nacional (UPN). Es especialista en estudios de género en tópicos relativos a juventud, identidad, masculinidad, violencia y formación profesional. Es responsable de la Especialidad de Género en Educación de la UPN. Colabora como ponente, instructor, conferencista, docente, asesor y evaluador en diversas instituciones y revistas, nacionales e internacionales, incluyendo programas de televisión. Ha sido profesor invitado en diversas instituciones de prestigio en los ámbitos de la salud, administración y educación. Su reciente publicación es el libro A Look Into Masculine Identity in Mexican Young men (México: UPN, 2017). Correo electrónico: jvillanueva@upn.mx 
Claudia Ivonne Hernández Ramírez. Licenciada en Psicología Educativa y Especialista de Género en Educación, Maestra en Desarrollo Educativo perteneciente a la línea de investigación Educación en Ciencias, por parte de la Universidad Pedagógica Nacional (UPN). Las líneas de investigación y trabajo giran en torno al estudio del quehacer docente, currículum, la escritura científica, género y educación, feminización en la educación y masculinidades. Asistente de investigación en la UPN desde 2013. Docente de educación básica en la Secretaría de Educación Pública (SEP) desde 2014. Partícipe en coloquios, conferencias y congresos como ponente en temáticas relacionadas con la perspectiva de género, feminización en la educación, roles y estereotipos y masculinidades. Es coautora de artículos indexados y capítulos de libros, principalmente, en tópicos como imágenes y lenguaje sexista, las mujeres en las organizaciones educativas y la división sexual del trabajo. Además, ha colaborado en campañas de asesoramiento, acompañamiento y apoyo a personas en situaciones de riesgo, vía virtual y presencial. Correo electrónico: cihernandez@upn.mx

Osiris Yomar Aparicio Hernández. Licenciada en Antropología Social por la Universidad Autónoma de Guerrero (UAGRO) y Especialista de Género en Educación por la Universidad Pedagógica Nacional (UPN). Cuenta con experiencia en el trabajo de campo en pueblos del estado de Guerrero, principalmente, en comunidades indígenas. Ha impartido talleres con perspectiva de género en primarias públicas y ha colaborado en proyectos para el municipio de Tixtla de Guerrero, Guerrero. Además, ha realizado censos, asambleas comunitarias y proyectos para el ayuntamiento de Tixtla de Guerrero. Tiene conocimiento en antropología visual, movimientos sociales, antropología urbana, antropología del turismo. Su labor está enfocada en el trabajo con grupos minoritarios y vulnerables. Correo electrónico: osijonas@gmail.com 